\title{
Gender Differences in Regional Cerebral Activity During Sadness
}

\author{
Frank Schneider, '* Ute Habel,' Christoph Kessler,' Jasmin B. Salloum,' \\ and Stefan Posse ${ }^{2}$ \\ ${ }^{1}$ Department of Psychiatry, University of Düsseldorf, Düsseldorf, Germany \\ ${ }^{2}$ Institute of Medicine, Research Center Jülich, Jülich, Germany
}

\begin{abstract}
Functional magnetic resonance imaging and echo-planar-imaging were used to investigate affect related gender differences in regional cerebral activity. The experiment was conducted using a standardized mood induction procedure. Blood-oxygen-level-dependent effect was measured in 13 male and 13 female healthy subjects, during both moods of happiness and sadness, respectively. Parallel to earlier neuroimaging findings, our results show brain activity in the amygdala of males during negative affect. Females failed to demonstrate a similar activation pattern despite matched subjective ratings of negative affect to males. Results point to differential regional cerebral correlates of emotional experience in males and females, which is suggestive of a more focal and subcortical processing of sadness in men. Hum. Brain Mapping 9:226-238, 2000. ๑ 2000 Wiley-Liss, Inc.
\end{abstract}

Key words: fMRI; BOLD-effect; emotion; mood induction; amygdala, gender differences

\section{INTRODUCTION}

In general, investigations have rarely been undertaken pertaining to gender variability, particularly in the area of neurobiological correlates of affect. However, quite interesting gender differences are noted in terms of the clinical manifestation of many psychiatric disorders. Notably, the incidence of clinical depression is higher in women. An important question that needs addressing is whether neurobiological substrates of affect processing in morphology or brain function show gender differences. In studies where different regional cerebral activation during mood in-

Contract grant sponsor: Deutsche Forschungsgemeinschaft (DFG); Contract grant number: Schn 362/6-1.

${ }^{*}$ Correspondence to: F. Schneider, Department of Psychiatry, University of Düsseldorf, Bergische Landstr. 2, 40629 Düsseldorf, Germany. E-mail: frank.schneider@uni-duesseldorf.de

Received for publication 1 November 1999; accepted 28 December 1999 duction or discrimination [George et al., 1996; Gur et al., 1995] were observed, a neurobiological based gender difference in emotion processing has been proposed. The same proposition is made for variances in skin conductance response during viewing of emotional film clips [Kring and Gordon, 1998]. Moreover, differences between the two sexes were found in emotional processing [Burton and Levy, 1989; Duda and Brown, 1984]. Women have been noted to be more expressive than men [Asthana and Mandal, 1998; Kring and Gordon, 1998; McConatha et al., 1997]. Observations of varying facial expressions between men and women [Alford, 1983; Frisch, 1995] may similarly reflect neurobiologically based gender differences. Nevertheless, the divergent results between both gender groups with regard to behavior could be attributed to normative social sex roles as well [Grossman and Wood, 1993].

Hence, our interest is directed toward an understanding of the underlying neurobiological correlates 
of gender differences in functional cerebral correlates of emotional states in healthy men and women. Of the studies thus far conducted on gender, differences were reported in regional cerebral blood flow ( $\mathrm{rCBF}$ ) during both rest and different emotional states [George et al., 1996], and with women showing more limbic and paralimbic activation during sadness.

There is an ongoing discussion pertaining to hemispheric asymmetry in the processing of emotion, favoring a right hemispheric dominance [Adolphs et al., 1996; Davidson, 1993]. The hypothesis on emotional valence proposes a greater right hemispheric involvement for negative emotional stimuli, whereas a greater left hemipheric involvement is associated with material of positive valence [Heller, 1990]. A right hemispheric dominance for emotional expression has been deduced, for example, from the asymmetry found in emotional facial expressions, especially for negative emotions, expressed more intensively on the left side [Asthana and Mandal, 1998; Borod et al., 1988]. Furthermore, sad mood induction was associated with decelerated left visual field processing (right hemisphere) [Lavadas et al., 1984]. Hemispheric asymmetries have also been shown in the processing of sad vs. happy facial expressions, with a right hemisphere advantage in processing speed for sad expressions [Moretti et al., 1996]. In general, studies of facial and verbal emotion perception have provided evidence for the right hemispheric dominance, as well as for valencerelated asymmetries. However, some results contradict predictions of the valence hypothesis. For example, it was shown that the selective presentation of emotional film clips to the right hemisphere (with contact lenses) did not produce greater negative ratings [Otto and Yeo, 1993]. Experiments of dichotic listening also lend support to the assumption of the right hemispheric dominance for emotional material, whereas they fail to do so for the valence hypothesis [Bulman-Fleming and Bryden, 1993; Erhan et al., 1998]. In such studies, variables as the emotional task requirement (perception of emotion, facial expression, emotional experience) as well as the method for investigating cerebral asymmetries (dichotic listening, contact lenses, tachistoscopic procedures) exert influence on outcome, and may thus explain the different results.

With respect to cerebral asymmetries, gender differences have also been observed. Pronounced asymmetry was observed for negative emotions [Asthana and Mandal, 1998] less for positive emotions [Borod et al., 1983] in females compared to males. In the perception of emotion, only trends for sex differences were reported, with no interactions between gender of the stimulus face and gender of the subject [Hugdahl et al., 1993].

We employed a standardized mood induction procedure to investigate possible gender differences using functional magnetic resonance imaging (fMRI) based on blood-oxygen-level-dependent (BOLD) contrast. Our aim was to explore the neurobiological correlates of happy and sad mood states compared to a control-neutral mood condition. Ecologically valid and socially relevant emotional stimuli applicable in functional neuroimaging studies were employed [Schneider et al., 1994a]. The stimuli were standardized and capable of obtaining reliable mood changes in subjects. Mood changes as a result of such mood induction per se have been confirmed in earlier studies on a behavioral level [self report and facial expression; Schneider et al., 1994a; Weiss et al., 1999]. Characteristic valence specific regional cerebral and autonomic effects of happy and sad mood induction were demonstrated by measuring regional brain activity with ${ }^{133}$ Xenon [Schneider et al., 1994b], $\mathrm{H}_{2}{ }^{15} \mathrm{O}-$ PET [Schneider et al., 1995], and fMRI [Schneider et al., 1997, 1998]. Together, the findings suggest a special role of the amygdala in the processing of negative affect during the mood induction procedure.

\section{MATERIALS AND METHODS}

\section{Subjects}

Participants (13 male and 13 female) were all healthy subjects (males: mean age \pm SD, $31.69 \pm 7.65$ years (range 20-46), education $13.38 \pm 3.40$ years; females: age $=30.77 \pm 6.78(23-43)$, education $12.77 \pm$ 2.77). The protocol was approved by the Institutional Review Board of the School of Medicine of the University of Düsseldorf and is in accordance with the Code of Ethics of the World Medical Association. Following a complete description of the study to the subjects, written informed consent was obtained from each subject. The usual exclusion criteria for MRI were applied. Participants underwent an intensive screening using comprehensive assessment procedures for medical, neurological, and psychiatric history [similar to Shtasel et al., 1991]. Data on the healthy male subjects have been presented previously in a study that compared normal controls to schizophrenic patients [Schneider et al., 1998].

\section{Mood-induction procedure}

Subjects participated in a standardized mood induction procedure, described previously [Schneider et al., 
TABLE I. Mean ratings (and SD) for the emotional self-rating scale (ESR) during the different conditions

\begin{tabular}{|c|c|c|c|c|c|c|}
\hline \multirow[b]{2}{*}{ ESR } & \multicolumn{2}{|c|}{ Happiness } & \multicolumn{2}{|c|}{ Sadness } & \multicolumn{2}{|c|}{ Control } \\
\hline & Men & Women & Men & Women & Men & Women \\
\hline Happiness & $3.53( \pm 1.05)$ & $3.61( \pm 0.77)$ & $1.38( \pm 0.65)$ & $1.00( \pm 0.00)$ & $2.46( \pm 1.05)$ & $2.23( \pm 1.17)$ \\
\hline Sadness & $1.23( \pm 0.83)$ & $1.00( \pm 0.00)$ & $3.53( \pm 1.05)$ & $3.53( \pm 0.88)$ & $1.15( \pm 0.55)$ & $1.07( \pm 0.28)$ \\
\hline Anger & $1.23( \pm 0.44)$ & $1.07( \pm 0.28)$ & $1.61( \pm 1.04)$ & $1.46( \pm 0.88)$ & $1.46( \pm 0.77)$ & $1.23( \pm 0.60)$ \\
\hline Disgust & $1.15( \pm 0.55)$ & $1.00( \pm 0.00)$ & $1.07( \pm 0.28)$ & $1.00( \pm 0.00)$ & $1.07( \pm 0.28)$ & $1.00( \pm 0.00)$ \\
\hline Fear & $1.15( \pm 0.38)$ & $1.00( \pm 0.00)$ & $1.38( \pm 0.51)$ & $1.46( \pm 0.52)$ & $1.07( \pm 0.28)$ & $1.07( \pm 0.28)$ \\
\hline Surprise & $2.23( \pm 0.83)$ & $1.92( \pm 0.95)$ & $1.30( \pm 0.63)$ & $1.69( \pm 1.25)$ & $2.38( \pm 0.96)$ & $2.61( \pm 1.12)$ \\
\hline
\end{tabular}

1994a]. Briefly, the task has two components, one consisting of 40 happy and the other of 40 sad slides of facial expressions, posed by professional actors and actresses. The models were draped in black fabric and photographed against a black backdrop to eliminate all clothing and ambient distracters. In constructing the stimulus set, we used 169 slides for which more than $90 \%$ of the raters in the study of Erwin et al. [1992] agreed upon the portrayed target emotion of happy and sad. The slides were presented to six raters who rated the genuineness of the expression (yes/no) and whether only one emotion and not emotional blends were displayed (yes/no). Additionally, they rated the intensity of the expressed target emotion on a 5-point Likert-type scale (1: not at all-5: most intense). Only unitary and genuine facial expressions were included in the test. No more than three different pictures of one single actor in each of the two tasks were allowed in the final test. These straight angle monochromatic photographs included 10 male and 11 female actors in the sad, and 11 male and 11 female actors in the happy condition. The slides in each of the two tasks (happy mood induction, sad mood induction) were presented in random order with the constraints that no more than three slides of the same sex and only one slide of a single actor be found in a set of seven slides. The experiment comprised three conditions (happy mood induction, sad mood induction, control task) during which time fMRI data were acquired. Stimuli consisted of happy and sad facial expressions projected onto a screen that was positioned in front of the scanner. A mirror placed on the top of the RF-coil made the stimuli visible to the subjects. The three conditions were administered in counterbalanced order (Latin square design) with the control condition amid the two emotional conditions to minimize carryover effects. Each condition included an activation phase preceded by a resting baseline of the same duration. With the help of a response device, subjects moved on to the next face by pressing response buttons using both thumbs simultaneously.
The pace for moving on to the next face was controlled individually by subjects according to their individual arousal level. The instructions were as follows: "During this task, I would like you to try to become happy [sad]. To help you do that, I will be showing you slides with faces expressing happiness [sadness]. Look at each face and use it to help you to feel happy [sad]." The control condition consisted of a gender differentiation task. Subjects determined the gender of the character in each slide by pressing the left/right response button, respectively.

The dependent measure for the mood induction effect was the positive and negative affect schedule (PANAS) [Watson et al., 1988], a 5-point unipolar intensity scale, which includes ratings for factor referenced emotional descriptors for orthogonal positive and negative dimensions. The scale required a rating of "How did you actually feel in the last minutes?" Furthermore, an emotional self-rating scale (ESR) [Schneider et al., 1994a] was applied that included a 5-point unipolar intensity scale used as a manipulation check to ascertain the specificity of the experienced emotion (see Table I).

\section{Imaging protocol}

fMRI of the brain was acquired using a 1.5T Magnetom Vision MR scanner (Siemens). Axial slices were measured using anatomical MRI (T1 weighted, 16 slices, slice thickness $3 \mathrm{~mm}$, gap $1 \mathrm{~mm}$, TR $704 \mathrm{msec}$, TE $12 \mathrm{msec}$, matrix $256 \times 256$, FOV $192 \mathrm{~mm}$ ) with the same orientation for the acquired functional data. Slice position was choosen parallel to the intercommissural line (anterior commissure-posterior commissure, ACPC), covering mainly subcortical-limbic and associated cortical areas. Functional images were obtained using a BOLD contrast echo-planar-imaging (EPI) technique (slice thickness $3 \mathrm{~mm}$, TR $8 \mathrm{sec}$, acquisition time $3 \mathrm{sec}$, TE $46 \mathrm{msec}$, matrix $64 \times 64$, FOV $192 \mathrm{~mm}$, $\alpha 90^{\circ}$ ). Baseline and activation tasks consisted of 25 repeated measurements each. There were 3-min 
breaks between conditions. Image acquisition during fMRI was subject to hardware and software limitations at the time the study was initiated. Limited immediate storage capacity at the time the study was initiated restricted data to a minimal number of slices $\times$ time points $\times$ conditions.

\section{Statistical analysis}

The dependent measure for quantifying the mood induction effect was derived from the ratings of positive and negative scores of the PANAS. The positive emotional score consisted of the sum of the ten positive emotional items and the negative emotional score was the sum of the ten negative items. These scores served as dependent measures in the statistical analysis (MANOVA). A repeated measures three-way ANOVA, with task (happy, sad, control), rating scale (happy, sad), and gender (male, female) as a betweensubject variable, was performed to check the mood induction manipulation. The scale-by-task interaction served as a test for the hypothesis (mood-induction effect $>0$ ).

Functional data were corrected for head motion. The realignment was done with the SPM 96b software package (University College, Department of Cognitive Neurology, London). The tenth image in the time series was used as reference. This correction reduces motion artifacts by a least square rigid body transformation (translation in $\mathrm{x}, \mathrm{y}, \mathrm{z}$ direction and rotation around these three main axes). Simple linear baseline drifts during an experimental run (baseline-stimulation phase within one condition) are corrected for by our algorithm that evaluates the signal mean values for each phase. Averaging the signal within a particular phase renders explicit low pass filtering of the raw data unnecessary. The anatomical slices were superimposed on the mean image of the realigned dataset of each experimental condition and coregistered with MPITOOL 2.36 (MPI for Neurological Research, Cologne), thus creating a corrected anatomical dataset for each individual condition. This procedure accounts for shifts present in the two datasets. Furthermore, it verified the correct identification of regionsof-interest (ROIs) that were to be defined at a later stage of data processing. For the superposition of both, we determined the $A C$ as a corresponding reference point. Thirteen homotopic regions were defined anatomically with STIMULATE 5.0 (University of Minnesota, Center of Magnetic Resonance Research, Minneapolis, MN, USA) for each subject on several slices of the coregistered MRI plane (Fig. 1). Data analysis was performed initially with two addi- tional regions, brainstem and gyrus rectus. Because of methodological constraints of the functional data, insufficient signal-to-noise-ratio precluded further analysis.

ROIs were defined to convey a representative part of the whole region (central punch biopsy) and to contain mainly grey matter. Regions included in the analysis were as defined, and comprised mainly grey matter. They are the amygdala (near the outer end of the caudatum at the tip of the inferior horn of the lateral ventricle), hippocampus (defined as C-shaped structure, below the corpus callosum extending with its main part along the floor of the temporal horn of the lateral ventricle), thalamus (egg-shaped structure, forming the walls of the third ventricle, extending anteriorly to the interventricular foramen and posteriorly overlapping the midbrain, as defined on the three slices representing it in its greatest extent), anterior cingulate (small part anterior to the corpus callosum, Brodman area 32, 33) and posterior (small part posterior to the corpus callosum, Brodman 31, 23), orbitofrontal cortex (defined on the slice about $8 \mathrm{~mm}$ above the gyrus rectus, on the medial and ventral surface of the frontal lobe), dorsolateral prefrontal cortex (Brodman 9, 10, 46 sparing FEF, 8 and PMC, 6), temporal superior cortex (at the outer wall of the lateral sulcus, Brodman 22), temporal medial cortex (from the hippocampal head just beneath the amygdala and extending posteriorly until fornix), temporal inferior cortex (outer part between the inferior temporal sulcus and the lateral occipitotemporal sulcus, Brodman 20), occipital cortex (caudal pole of the occipital lobe, predominantly on its medial aspects), precuneus (medial part of the parietal lobe), and cerebellum (delineation of both hemispheres).

ROIs were then combined three-dimensionally before overlay with the activity-distribution image. These anatomically defined 3D regions were transferred on to the functional dataset of lower spatial resolution $(0.75 \mathrm{~mm}$ vs. $3 \mathrm{~mm})$. Only functional voxels with an anatomic coverage exceeding 75\% were included in the regional analysis. As for spatial normalization of the data, it proved impossible to perform because the composition of 16 slices fell short of covering the whole brain, leading to unacceptable distortions during normalization. Only voxels surviving a threshold of about 5 times above noise level for the functional data were considered to hold valid data, and were used for further analysis in order to avoid the problem of susceptibility artifacts (drop-outs) close to larger cavities. Finally, mean values for baseline and activation periods were extracted from each 3D region individually. 
TABLE II. Significant effects for the different groupings of regions and the single ROls

\begin{tabular}{|c|c|c|}
\hline Region & Effect & $F(d f), P-t(d f), P$ \\
\hline PANAS & $\begin{array}{l}\text { scale-by-task } \\
\text { task } \\
\text { scale }\end{array}$ & $\begin{array}{l}F(2,48)=37.41, P<0.0001 \\
F(2,48)=4.09, P<0.02 \\
F(1,24)=422.95, P<0.0001\end{array}$ \\
\hline \multicolumn{3}{|l|}{ FMRI } \\
\hline Subcortical-limbic & $\begin{array}{l}\text { gender-by-task-by-laterality } \\
\text { gender-by-region-by-task-by-laterality }\end{array}$ & $\begin{array}{l}F(2,48)=5.59, P<0.008 \\
F(4,96)=3.35, P<0.03\end{array}$ \\
\hline Amygdala & gender-by-task-by-laterality & $F(2,48)=5.49, P<0.007$ \\
\hline Thalamus & task & $F(2,48)=8.13, P<0.003$ \\
\hline Frontal-limbic & $\begin{array}{l}\text { gender } \\
\text { region } \\
\text { task-by-laterality } \\
\text { region-by-laterality } \\
\text { gender-by-region }\end{array}$ & $\begin{array}{l}F(1,24)=4.46, P<0.045 \\
F(3,72)=4.02, P<0.02 \\
F(2,48)=3.83, P<0.04 \\
F(3,72)=6881.13, P<0.0001 \\
F(3,72)=3.33, P<0.04\end{array}$ \\
\hline Temporal & $\begin{array}{l}\text { region } \\
\text { task } \\
\text { gender-by-laterality }\end{array}$ & $\begin{array}{l}F(2,48)=9.11, P<0.004 \\
F(2,48)=5.43, P<0.01 \\
F(1,24)=4.86, P<0.04\end{array}$ \\
\hline Control & $\begin{array}{l}\text { region } \\
\text { task } \\
\text { gender-by-region-by-task } \\
\text { gender-by-task-by-laterality } \\
\text { gender-by-region-by-task-by-laterality }\end{array}$ & $\begin{array}{l}F(2,48)=24.25, P<0.0001 \\
F(2,48)=5.69, P<0.009 \\
F(4,96)=3.40, P<0.046 \\
F(2,48)=3.90, P<0.03 \\
F(4,96)=3.19, P<0.04\end{array}$ \\
\hline Cerebellum & $\begin{array}{l}\text { task } \\
\text { laterality } \\
\text { gender-by-task-by-laterality }\end{array}$ & $\begin{array}{l}F(2,48)=4.03, P<0.03 \\
F(1,24)=4.93, P<0.04 \\
F(2,48)=5.40, P<0.02\end{array}$ \\
\hline Occipital cortex & $\begin{array}{l}\text { task } \\
\text { control task vs. happy mood } \\
\text { sad mood vs. happy mood }\end{array}$ & $\begin{array}{l}F(2,48)=8.61, P<0.001 \\
t(25)=-2.33, P=0.03 \\
t(25)=-4.21, P=0.0003\end{array}$ \\
\hline
\end{tabular}

The relative signal intensity (SI) change was then calculated from the mean values according to $\left[\left(\mathrm{SI}-\mathrm{SI}_{\mathrm{BL}}\right) / \mathrm{SI}_{\mathrm{BL}}\right]$, where $\mathrm{SI}_{\mathrm{ACT}}$ and $\mathrm{SI}_{\mathrm{BL}}$ refer to mean SI during activation (ACT) and baseline (BL), respectively. Therefore, signal changes reflect changes from baseline. Evaluation of only relative signal changes (which encompasses a model of relative scaling of a signal of interest with global blood flow) guarantees for intersubject comparison. These relative signal changes served as dependent measures in the statistical analysis (MANOVA).

Regions were grouped into target and nontarget ROIs in view of anatomical relations and the differential functional importance of subcortical-limbic, frontal-limbic, and temporal regions in emotional processing. The grouping was also performed on the assumption that activation will not be found in all regions during one condition. We also aimed at covering a representative part of the limbic system together with related regions. The remaining areas represented control regions. MANOVAs were done separately for the four regional groupings because of the hypothesized group differences occurring in specific regions only. Factors were gender (male, female), laterality (left, right), region (three subcortical-limbic, four frontal-limbic, three temporal, three control regions), and task (happy mood, sad mood, control) with region, task, and laterality used as repeated measures factors. Greenhouse-Geisser corrections were applied. Significant group-by-region interactions were decomposed by post-hoc tests (Scheffé) (see Table II).

To ascertain that ROI-definitions were comparable between two extensively trained raters, interrater-reliability on the SI change was assessed [Bartko et al., 1976]. Hence, intraclass correlation coefficients (ICC) were calculated for each region of three subjects. All ROIs demonstrated $r_{\text {ICC }}$ greater than .95 and were used for further analysis. Furthermore, we checked for the geometric overlap of the corresponding ROIs between raters based on the lowresolution functional images. Mean overlap exceeded $95 \%$, rendering ROI definitions of the two raters sufficiently reliable. 


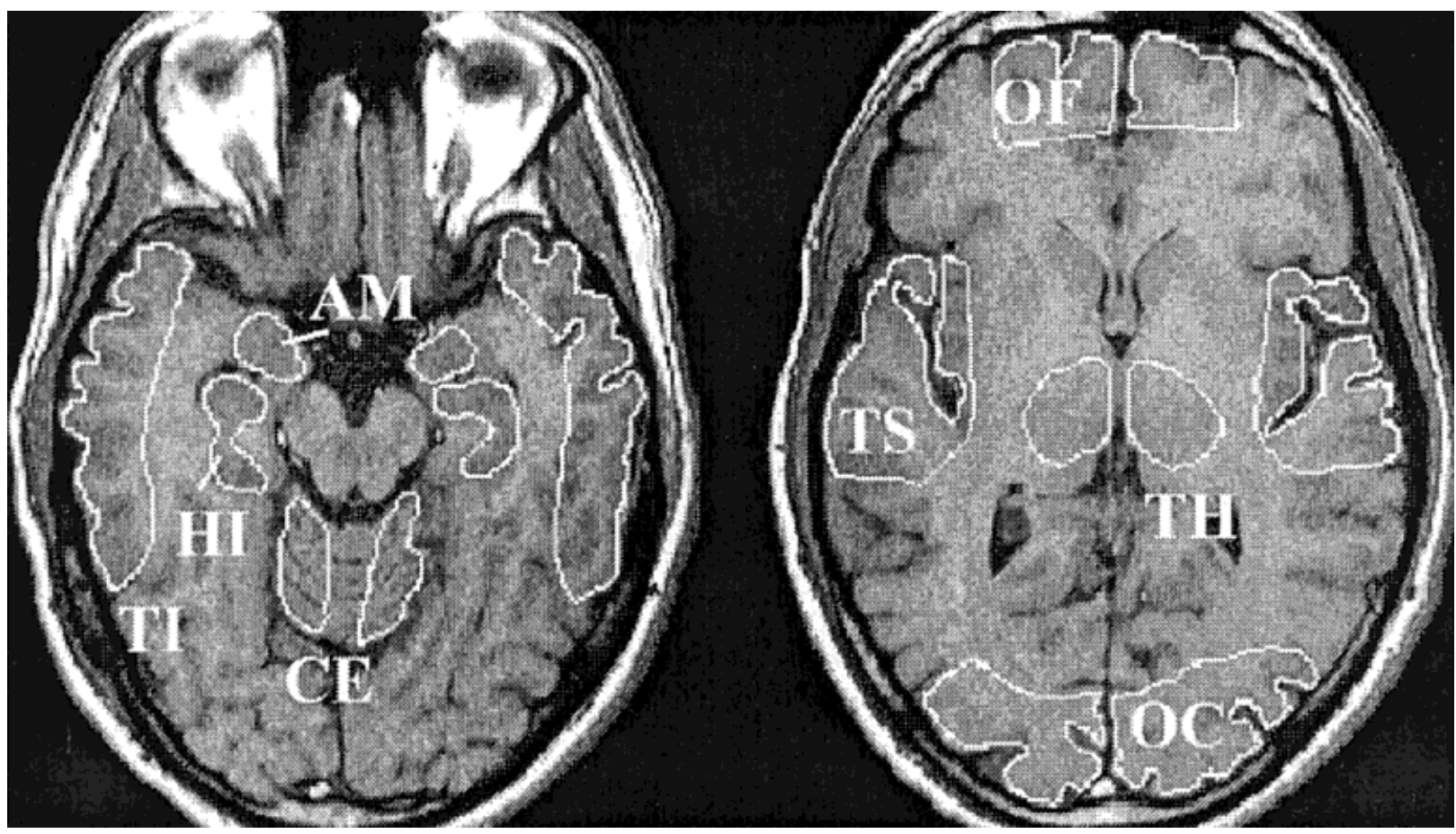

Figure I.

Illustration of anatomically defined regions on MRI: Subcorticallimbic regions: AM, Amygdala; HI, Hippocampus; TH, Thalamus; Frontal-limbic: Cingulate gyrus-anterior; Cingulate gyrus-pos-

\section{RESULTS}

PANAS

Subjective ratings demonstrated more negative affect during the sad mood induction and less negative affect during the happy mood induction. Likewise, more positive affect was present during happy mood induction compared to sad mood induction (Fig. 2). The ANOVA of the PANAS data yielded the expected scale-by-task interaction $(F(2,48)=37.41, P<0.0001)$, and a task $(F(2,48)=4.09, P<0.02)$ as well as a scale effect $(F(1,24)=422.95, P<0.0001)$, without any gender differences.

\section{FMRI}

For the subcortical-limbic region group, the statistical analysis of the fMRI data showed a significant gender-by-task-by-laterality $(F(2,48)=5.59, P<0.008)$ and gender-by-region-by-task-by-laterality interaction $(F(4,96)=3.35, P<0.03)$. This interaction enabled further analysis to be performed for each region separately. An ANOVA for the amygdala revealed only a gender-by-task-by-laterality interaction $(F(2,48)=$ terior; Dorsal lateral prefrontal; OF, Orbito frontal; Temporal: TI, Inferior temporal; Mid-temporal; TS, Superior temporal; Control: CE, Cerebellum; OC, Occipital cortex; Precuneus.

5.49, $P<0.007)$. Post-hoc comparisons showed a significant gender difference only for the right amygdala activation during sadness (Diff crit $=1.25$; Fig. 3). Male subjects demonstrated a right amygdala activation compared to baseline during negative mood that was not present in females.

Controlling for the possible influence of differences in ROI size between men and women, volume size of

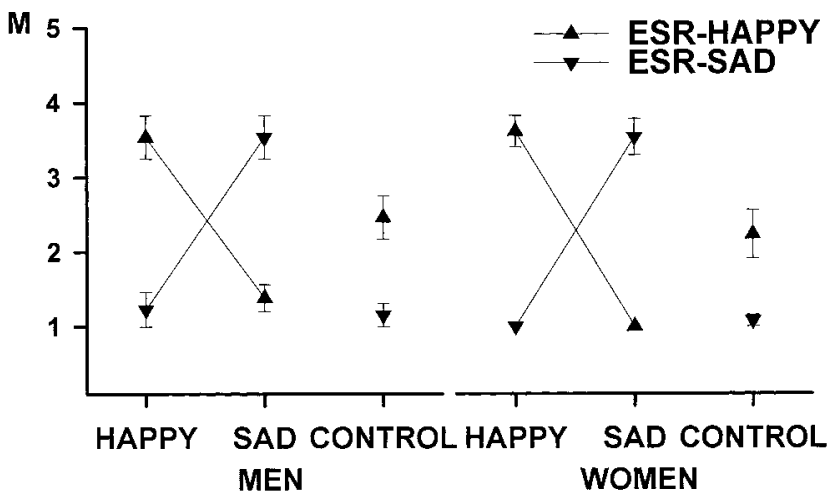

Figure 2.

Emotional self-ratings assessed with the ESR (mean $\pm \mathrm{SE}$ ) of 13 healthy males and 13 healthy females for happy and sad mood induction and a cognitive, nonemotional control task. 


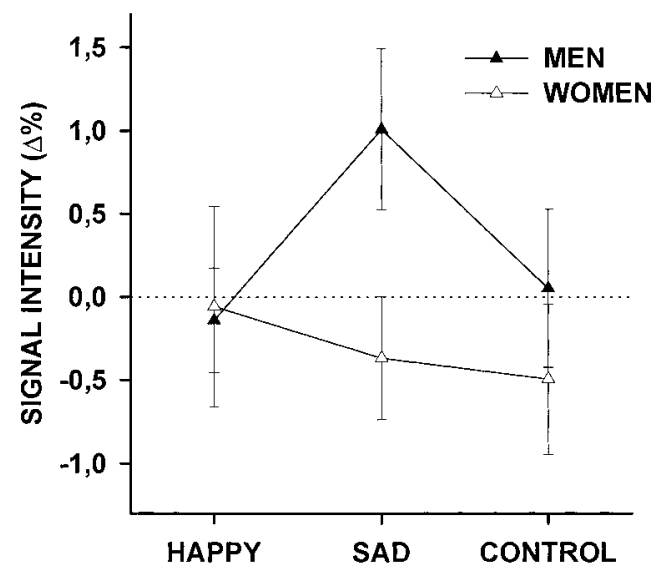

Figure 3.

Effect of sad mood induction on cerebral activation (signal intensity $\pm \mathrm{SE}$ ) in 13 men and 13 women. The abscissa shows the three experimental conditions, the ordinate shows the relative $\mathrm{SI}$ changes for the right amygdala.

the amygdala was calculated and yielded comparable volumes between genders (women, $1.13 \pm 0.20 \mathrm{~cm}^{3}$; men, $1.13 \pm 0.40 \mathrm{~cm}^{3}$ ), without any asymmetries. This analysis relied on the volume information provided by the anatomical slices (T1), on which the amygdala was identified. Therefore, our approach represents only an approximate volume of the actual volume of the amygdala. To determine an exact volume, a 3D dataset would have been required, which would provide information of the whole structure.

In the hippocampus, no differential cerebral activation effects were observed, whereas tasks produced only a different activation pattern in the thalamus $(F(2,48)=8.13, P<0.003)$. No further significant main effects or interactions could be observed in these or any other region of the subcortical-limbic region group.

For frontal-limbic areas, a main effect for gender $(F(1,24)=4.46, P<0.045)$, region $(F(3,72)=4.02, P<$ $0.02)$, and a task-by-laterality $(F(2,48)=3.83, P<0.04)$, region-by-laterality $(F(3,72)=6881.13, P<0.0001)$, and gender-by-region interaction $(F(3,72)=3.33, P<$ 0.04) emerged.

Analysis for temporal regions yielded main effects for region $(F(2,48)=9.11, P<0.004)$, task $(F(2,48)=$ $5.43, P<0.01)$, and a gender-by-laterality interaction $(F(1,24)=4.86, P<0.04)$.

For control regions, significant effects were observed for region $(F(2,48)=24.25, P<0.0001)$, task $(F(2,48)=5.69, P<0.009)$, and the interactions gender-by-region-by-task $(F(4,96)=3.40, P<0.046)$, gender-by-task-by-laterality $(F(2,48)=3.90, P<0.03)$, and gender-by-region-by-task-by-laterality $(F(4,96)=3.19$, $P<0.04)$. Therefore, a similar decomposition of a meaningful interaction (gender-by-region-by-task), like that for subcortical regions, was possible only for control regions. For the cerebellum, a main effect for task $(F(2,48)=4.03, P<0.03)$ and laterality $(F(1,24)=$ 4.93, $P<0.04)$ and a gender-by-task-by-laterality interaction $(F(2,48)=5.40, P<0.02)$ emerged. Females exhibited a stronger cerebellar participation during the control task than males (Diff crit $=0.73$ ). A task effect was seen in the occipital cortex $(F(2,48)=8.61$, $P<0.001)$. The control task produced more activation in the occipital cortex than the happy mood induction $(t(25)=-2.33, P=0.03)$. In the same region sad mood elicited more activation than the happy mood induction $(t(25)=-4.21, P=0.0003)$. No significant effects were seen for the precuneus.

\section{Correlation analysis}

Amygdala activation could be interpreted as an important neurobiological substrate of sadness, a finding that was supported by correlation analysis of subjective ratings and signal changes (Fig. 4). In male subjects, signal intensities in the right amygdala increased with intensified subjective experience of sadness $(r=$ $0.64, P<0.02)$. The same could not be confirmed for women $(r=0.14$, n.s. $)$ and also not for the left amygdala.

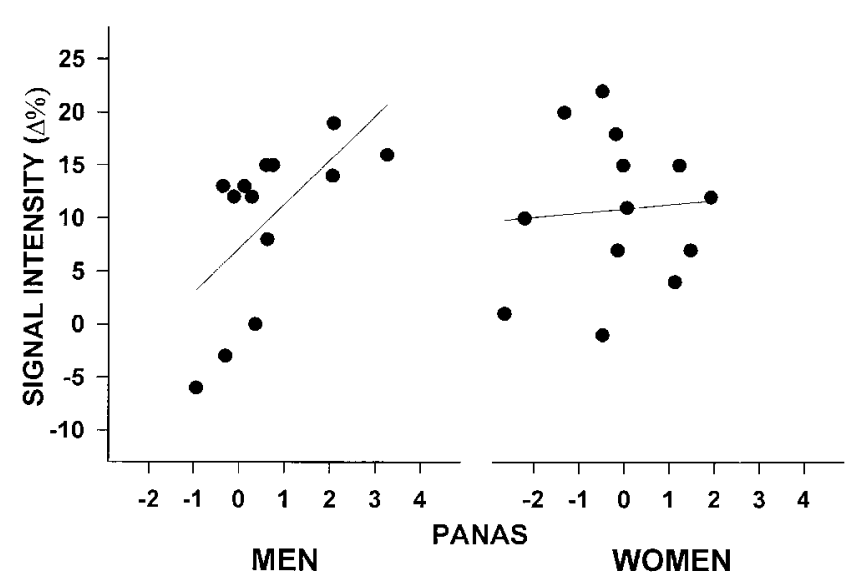

Figure 4.

Correlation between subjective mood-induction effect (PANAS: positive score minus negative score) during sad mood induction and cerebral activation ( $\Delta \%=$ percent change in signal intensity) in the amygdala during sadness for 13 men and 13 women, respectively. The abscissa shows the PANAS difference scores, the ordinate shows the relative SI changes for the right amygdala. 


\section{DISCUSSION}

\section{Gender differences}

Our results suggest the presence of gender differences in regional cerebral signal changes for negative affect. Amygdala activation, which was associated with the subjective experience of sadness, corresponded to sad mood in males. Women, on the other hand, showed no corresponding signal changes, despite similar ratings of experienced sadness. In view of our results, we speculate that sad mood in women produces less concentrated and less lateralized brain activation compared to men. This is in line with results found for the cerebral processing of language [Shaywitz et al., 1995]. Similarly, in PET studies, women during induced sadness showed bilateral activation without asymmetries [George et al., 1995; Lane et al., 1997; Pardo et al., 1993]. An effect of mood induction during the control task as a result of recognizing emotional facial expressions can be ruled out in this study. The failure of the control condition to produce the same subjective mood changes as mood induction, along with any comparable regional cerebral activation, in spite of consisting of the same stimuli used for the mood induction condition, serves to confirm it as a nonemotional cognitive task.

A greater cerebellar participation during the control task was observed in our female sample compared to the male group. Higher brain metabolism in the cerebellum of women was likewise demonstrated during baseline measurements in an earlier PET study [Volkow et al., 1997]. Other findings corroborate the results from our male subjects. Gur et al. [1995], using $\mathrm{PET}$, demonstrated in men relative to women a greater relative glucose metabolism in temporo-limbic regions, as well as a greater absolute metabolism in the amygdala and the hippocampus during resting states. In women, they detected a higher relative metabolism in the middle and posterior cingulate gyrus. The reported variances may explain differences in the cerebral correlates of emotional processing in both the gender groups, as the two regions (amygdala, cingulate cortex) are involved in emotional processing and are part of the limbic network. However, the findings of gender differences with regard to regional cerebral glucose metabolism have not always been consistent [Miura et al., 1990].

Behavioral differences could also account for the gender differences we detected. Women may opt for strategies in achieving sadness that differ from men, involving more cognitive strategies and internal cues. Men may focus more on external visual stimulus ma- terial, which seems to suggest more amygdala participation. Women are also said to be more emotional, and behaviorally more emotionally expressive [Kring and Gordon, 1998] (e.g., the presentation of socially stressful situations have been shown to elicit more tension, distress, and fear in women than in men [Morris-Prather et al., 1996]). One could speculate that men had to exert a greater effort into experiencing sadness and consequently demonstrated increased amygdala involvement.

A recent study applying photic stimulation also reported lower BOLD responses in women than in men. Contributing to much of the differences was a prevailing lateralization to the right hemisphere in men [Levin et al., 1998]. The authors point to a possible influence of baseline hemoglobin concentration in blood on the BOLD effect (e.g., altering hemoglobin concentration alters BOLD signal). Considering the particular amygdala activation characteristics (amygdala participation, especially at the very early stages of processing, along with weaker signal increases observed in subcortical regions), it may be that, particularly in this region, the hemoglobin plays an influential role on BOLD effects. The lower baseline hemoglobin concentration of women could release a greater and earlier signal increase compared to men to compensate, resulting in an early amygdala response not detected with our temporal resolution. Our limited temporal resolution presumably allowed us to map only the delayed activation in men.

\section{Amygdala activation and the subjective experience of emotion}

Because of the multiple connections between the amygdala and various cortical and subcortical areas, and the fact that the amygdala receives processed input from all the sensory systems, amygdala participation is essential during the initial phase of stimulus evaluation. The appraisal function of the amygdala, combining external cues with an internal reaction, reflects the starting point for a differential emotional response including the subjective experience of an emotion. Hence, as suggested from our previous results, the subjective feeling also seems released and modulated by the amygdala. This response characteristic of the amygdala has been demonstrated in animal studies [Gaffan, 1992; Rolls, 1992]. It is also supported by neuroimaging findings in humans. The initial stimulation of the amygdala has been demonstrated to release an orienting reflex with attention increases and autonomic reactions relevant for producing a shift in attention for ecologically valid stimuli. In this func- 
tional context, the response to stimuli irrespective of their valence becomes clear [Hamann et al., 1999]. Only following a longer stimulus duration have full emotional reactions been observed in different animals [Gloor, 1986], lending support to the hypothesis of an amygdala participation during the subjective experience of emotion in humans.

Evidence for the special role of the amygdala in the processing of negative emotional material is also provided by a number of experiments [Ketter et al., 1996; Phillipps et al., 1997]. Amygdala activation was observed during the viewing of fearful faces using PET [Rowland et al., 1996] (four males, one female) and fMRI [Irwin et al., 1996] (six females). The emotion of fear, however, may implicate a differential response pattern than the subjective experience of sadness. Amygdala activation was similarly found for presentation of sad faces using PET [Blair et al., 1999] (13 males). With respect to the neurobiological substrates of the subjective component of affect following more direct mood induction methods, investigations on normal males and females using $\mathrm{H}_{2}{ }^{15} \mathrm{O}$ PET showed increased activity in the left amygdala during procaineinduced fear [Ketter et al., 1996] (17 males, 15 females). Amygdala activation was also detected in our male subjects, which corroborates our earlier findings [Schneider et al., 1995, 1997]. Previously, we described blood flow increases in the left amygdala during sad mood in a mixed group of males $(n=11)$ and females $(n=5)$ in an $\mathrm{H}_{2}{ }^{15} \mathrm{O}$ PET study [Schneider et al., 1995]. These changes correlated with shifts toward negative affect. Assessment of fMRI changes in blood oxygenation level dependent (BOLD) contrast in seven men and five women indicated similar results to the PET findings [Schneider et al., 1997]. Moreover, left amygdala activation was also found during happy mood induction.

More evidence for the role of amygdala during the subjective experience of negative affect comes from PET studies. In them, greater blood flow was shown in the left amygdala of depressed patients [Drevets et al., 1992]. In such patients, a correlation emerged between resting regional cerebral metabolic rate in the right amygdala and the dispositional negative affect as well [Abercrombie et al., 1998].

However, in spite of describing associated subjective experiences of emotion, amygdala activation was not always reported in neuroimaging studies applying various mood-induction techniques. Instead, those experiments consistently found an anterior cingulate cortex and prefrontal cortex involvement [Mayberg et al., 1999; Teasdale et al., 1999]. There are a number of possible reasons for these discrepancies. One critical point are the various methods of mood induction that are applied. Mayberg et al. [1999] tried to dissociate the induction phase from the affect phase by investigating healthy subjects during mood induction, and by comparing the results to depressed patients prior to and following recovery. Interestingly, results showed increased activity in limbic-paralimbic regions (subgenual cingulate, anterior insula) as well as decreased activity in neocortical regions in chronic and transient negative mood, with a reverse pattern seen during recovery from depression. However, visual material for mood induction was not used in their study. Instead, the task required recalling of sad personal experiences, thus leading to different activation patterns compared to our results. As has been shown in a number of findings, divergent brain regions may be implicated in externally and internally generated moods [Reiman et al., 1997]. Lane et al. [1997] found, for example, different regional rCBF changes because of film- (amygdala) or recall-induced (anterior insula) mood. However, even with externally induced emotion (sad film clips), amygdala activation could not always be demonstrated in healthy and depressed subjects [Beauregard et al., 1998].

This methodological consideration also applies to a more recent study of Teasdale et al. [1999], who employed picture caption pairs that evoked positive and negative feelings, and other caption pairs eliciting less emotion. FMRI data analysis of the investigated six healthy subjects (three male and three female), revealed a medial prefrontal activation, and an activation in the anterior cingulate, predominantly rightsided, for negative or positive picture caption pairs compared to the nonemotional irrelevant pairs. Evidence of amygdala activation did not surface. The lack of amygdala participation in the latter study compared to our study may be because of the fact, that in our mood-induction procedure, we combined a more direct mood-induction technique of perceptual emotional stimuli (emotional faces) along with cognitively elicited emotions (recall of personal events). Teasdale et al. [1999], on the other hand, relied only on an essentially cognitive and a more indirect method of emotion elicitation. Hence, this would support the hypothesis of amygdala activation reflecting only its participation during the initial phase of emotional processing (i.e., encoding and evaluation of visual emotional material). However, this pattern of amygdala activation seems to habituate very rapidly [Breiter et al 1996; Büchel et al., 1998; LaBar et al., 1998]. Our results of amygdala activation during longer-lasting periods of externally triggered mood states point alternately to amygdala involvement not only in the 
initial process of stimulus evaluation but also during the subjective experience of induced mood. A comparison between the studies of Ketter et al. [1996] and Javanmard et al. [1999] are yet another example of the different findings as a consequence of differing mood induction methods. The method used by Javanmard et al. [1999] comprised panic-induction in healthy volunteers by cholecystokinin- 4 injections, which failed to elicit amygdala activation. Ketter et al. [1996], on the other hand, found amygdala activation in those persons only that reported fear following procaine injections.

Pardo et al. [1993] and George et al. [1995] similarly did not report any amygdala involvement during sad mood in females, supporting in part our finding of lack of amygdala activation in this gender group. Evidence for primary participation of the inferior and orbitofrontal cortex [Pardo et al., 1993], the anterior cingulate, medial prefrontal, and mesial temporal cortex, as well as for the brainstem, thalamus, caudatum, and putamen [George et al., 1995] was yielded in those studies. Whereas, yet again, others reported a participation of the middle and posterior temporal cortex, cerebellum, midbrain, caudatum, and putamen [Lane et al., 1997]. It is understood that complex emotional states require more than only the participation of one region. A complex network interaction is involved in all emotional experience. It may be that these results demonstrate the possibility of experiencing negative emotions, yet without amygdala activation.

Finally, the differing outcomes may, last but not least, be influenced correspondingly by methodological differences (e.g., PET vs. fMRI), different dependent variables (BOLD, rCBF, metabolism), temporal resolutions of the measurement techniques, and the various analysis techniques.

\section{Cerebral asymmetry in emotional processing}

In this study, amygdala activation was restricted to the sad mood induction with signal changes demonstrated only on the right side. There is an ongoing discussion with respect to laterality in relation to negative affective processes and amygdala activity, ranging from unilateral left or right sided to bilateral activation. Moreover, a hemispheric lateralization of emotional processing is, as yet, not fully understood. Reports so far indicate a greater right hemispheric involvement [Davidson et al., 1990]. Our current results extend these findings to subcortical processes. In contrast, and as described previously, a predominantly left-sided activation was found using ${ }^{15} \mathrm{O}$-PET and MRI in healthy subjects during two preceding mood induction studies [Schneider et al., 1995, 1997]. The methodological differences may account for these results. On the other hand, it may be that there are activation shifts from one side of the hemisphere to the other during mood induction because of arousal changes, or as a reflection of different stages of processing. Because of different temporal resolutions of the methods, the left- or right-sided activation maximums may reflect results measured at different time points during different stages of processing. Because gender seems to play a role in these results, gender effects may also have contributed to the different findings with respect to laterality. The smaller sample sizes of our previous studies inhibited us from investigating gender differences to the extent that it was performed in this study. The lateralized response found here may also reflect the strategy subjects employed for a change in mood. A more language-based strategy would account for a modulation of the left hemisphere in the amygdala [Blair et al., 1999]. The complexity of lateralization effects had been demonstrated in an fMRI study [Phillipps et al., 1997], where the intensity of emotional material influenced the side of activation. The processing of intense fearful facial expressions indicated a greater right amygdala involvement, which shifted to a greater left-sided participation for the processing of less intense expressions. Besides the influence of arousal, a recent fMRI study confirmed the effect of valence on hemispheric lateralization [Canli et al., 1998]. A prevailing rightsided activation (inferior frontal, gyrus rectus) was observed for negative, relative to positive, emotional material, which was controlled for arousal, and a greater left-sided activation for positive relative to negative material (middle frontal, middle, and superior temporal). This finding is in line with many previous clinical and EEG results. However, the activation is never completely lateralized. New studies have to address the question of laterality with more adequate paradigms in greater detail.

A possible contributing factor to the lateralized effect and gender-specific findings in the amygdala could be because of possible asymmetries found in amygdala volume. A slightly larger right amygdala had been reported [Filipek et al., 1994] in healthy subjects. This observation is, however, contradicted by other reports, showing the reverse [Convit et al., 1999] or a lack of asymmetry [Mu et al., 1999]. In our volumetric analysis, we could not find any asymmetries regarding amygdala volume, neither for the male nor for the female group. Furthermore, gender differences in volume have not been described previously [Giedd et al., 1999; Mu et al., 1999; Murphy, 1986]. Our anal- 
ysis of amygdala volume confirmed this lack of gender differences.

Our results support the importance of the role of the amygdala in experiencing negative emotions such as sadness. However, in light of our data, this finding has to be limited to the male gender, because females produced a different response pattern. Influences resulting from biological differences (between gender) such as hemoglobin concentration need to be taken into account during future investigations and have to be set in relation to the BOLD effect. The restricted number of measurements (only few slices and data points) and the conservative method for image analysis relying on predefined MRI-based and standardized ROIs adds a further limitation to our study. A conventional fMRI data is sensitive to large vessel effects. Finally, global changes in cerebral perfusion as a result of the different mood states [Schneider et al., 1994b] could not be addressed with our regional approach. Furthermore, a better temporal resolution allows for an event-related analysis of activation, which may address gender differences in greater detail.

\section{CONCLUSIONS}

We conclude from these results that brain activity in subcortical-limbic regions, and in particular the amygdala, represent some of the neurobiological correlates of sadness in healthy males. Lacking similar activation, females may have different neurobiological substrates in affective processing, with brain activation seeming less focal and less lateralized. These differences are observed despite corresponding sad affect on a behavioral level. Females may, on the other hand, depend on alternative behavioral strategies that could likewise be reflected in the gender differences in neurobiological correlates of different mood states.

\section{ACKNOWLEDGMENTS}

We thank M. Grosse-Ruyken for assistance and H.-W. Müller-Gärtner and J. Shaw for advice.

\section{REFERENCES}

Abercrombie HC, Schaefer SM, Larson CL, Oakes TR, Lindgren KA, Holden JE, Perlman SB, Turski PA, Krahn DD, Benca RM, Davidon RJ. 1998. Metabolic rate in the right amygdala predicts negative affect in depressed patients. NeuroReport 9:3301-3307.

Adolphs R, Damasio H, Tranel D, Damasio AR. 1996. Cortical systems for the recognition of emotion in facial expressions. J Neurosci 16:7678-7687.
Alford RD. 1983. Sex differences in lateral facial facility: The effects of habitual emotional concealment. Neuropsychologia 21:567570 .

Asthana HS, Mandal MK. 1998. Hemifacial asymmetry in emotion expressions. Behav Modif 22:177-183.

Bartko JJ, Carpenter WT. 1976. On the methods and theory of reliability. J Nerv Ment Dis 163:307-317.

Beauregard M, Leroux JM, Bergman S, Arzoumanian Y, Beaudoin G, Bourgouin P, Stip E. 1998. The functional anatomy of major depression: An fMRI study using an emotional activation paradigm. NeuroReport 9:3253-3258.

Bishop KM, Wahlsten D. 1997. Sex differences in the human corpus callosum: Myth or reality? Neurosci Behav Rev 21:581-601.

Biver F, Lotstra F, Monclus M, Wikler D, Damhaut P, Mendlewicz J, Goldman S. 1996. Sex difference in 5HT2 receptor in the living human brain. Neurosci Lett 204:25-28.

Blair RJ, Morris JS, Frith CD, Perrett DI, Dolan RJ. 1999. Dissociable neural responses to facial expressions of sadness and anger. Brain 122:883-893.

Borod JC, Koff E, White B. 1983. Facial asymmetry in posed and spontaneous expressions of emotion. Brain Cogn 2:165-175.

Borod JC, Kent J, Koff E, Martin C, Alpert M. 1988. Facial asymmetry while posing positive and negative emotions: Support for the right hemisphere hypothesis. Neuropsychologia 26:759-764.

Breiter HC, Etcoff NL, Whalen PJ, Kennedy WA, Rauch SL, Buckner RL, Strauss MM, Hyman SE, Rosen BR. 1996. Response and habituation of the human amygdala during visual processing of facial expression. Neuron 17:875-887.

Buckner RL, Raichle ME, Petersen SE. 1995. Dissociation of human prefrontal cortical areas across different speech production tasks and gender groups. J Neurophysiol 74:2163-2173.

Büchel C, Morris J, Dolan RJ, Friston KJ. 1998. Brain systems mediating aversive conditioning: An event related fMRI study. Neuron 20:947-957.

Bulman-Fleming MB, Brydon MP. 1998. Simultaneous verbal and affective laterality effects. Neuropsychologia 32:787-797.

Burton LA, Levy J. 1989. Sex differences in the lateralized processing of facial emotion. Brain Cogn 11:210-228.

Canli T, Desmond JE, Zhao Z, Glover G, Gabrieli JDE. 1998. Hemispheric asymmetry for emotional stimuli detected with fMRI. NeuroReport 9:3233-3239.

Chugani DC, Muzik O, Chakraborty P, Mangner T, Chugani HAT. 1998. Human brain serotonin synthesis capacity measured in vivo with alpha-[C-11] methyl-L-tryptophan. Synapse 28:33-43.

Coffey CE, Lucke JF, Saxton JA, Ratcliff G, Unitas LJ, Billig B, Bryan RN. 1998. Sex differences in brain aging: A quantitative magnetic resonance imaging study. Arch Neurol 55:169-179.

Convit A, McHugh P, Wolf OT, de Leon MJ, Bobinski M, De Santi S, Roche A, Tsui W. 1999. MRI volume of the amygdala: A reliable method allowing separation from the hippocampal formation. Psychiat Res 90:113-123.

Davidson RJ. 1993. Hemispheric asymmetry and emotion. In: Scherer KR, Ekman P, editors. Handbook of methods in nonverbal behavior research. Cambridge: University Press, p 39-57.

Davidson RJ, Ekman Paul, Saron CD, Senulis JA, Friesen WV. 1990. Approach-withdrawal and cerebral asymmetry: Emotional expression and brain physiology: I. J Pers Soc Psychol 58:330-341.

De Lacoste MC, Horvath DS, Woodward DJ. 1991. Possible sex differences in the developing human fetal brain. J Clin Exp Neuropsychol 13:831-846.

Drevets WC, Videen TO, Price JL, Preskorn SH, Carmichael ST, Raichle ME. 1992. A functional anatomical study of unipolar depression. J Neurosci 12:3628-3641. 
Duda PD, Brown J. 1984. Lateral asymmetry of positive and negative emotions. Cortex 20:253-261.

Erhan H, Borod JC, Tenke CE, Bruder GE. 1998. Identification of emotion in a dichotic listening task: Event-related brain potential and behavioral findings. Brain Cogn 37:286-307.

Erwin RJ, Gur RC, Gur RE, Skolnick B, Mawhinney-Hee M, Smailis J. 1992. Facial emotion discrimination: I. Task construction and behavioral findings in normal subjects. Psychiat Res 42:231-240.

Esposito G, Van Horn JD, Weinberger DR, Berman KF. 1996. Gender differences in cerebral blood flow as a function of cognitive state with PET. J Nucl Med 37:559-564.

Filipek PA, Richelme C, Kennedy DN, Caviness VS Jr. 1994. The young adult brain: An MRI-based morphometric analysis. Cereb Cortex 4:344-360.

Frisch I. 1995. Mimisches Verhalten von Frauen und Männern in gleichgeschlechtlichen dyadischen Interaktionen [Facial activities of women and men in dyadic interactions with a partner of same sex.]. Z Diff Diagn Psychol 16:33-42.

Gaffan D. 1992. Amygdala and the memory of reward. In: Aggleton JP, editor. The amygdala: Neurobiological aspects of emotion, memory, and mental dysfunction. New York: Wiley-Liss, p 471483.

George MS, Ketter TA, Parekh PI, Horwitz B, Herscovitch P, Post RM. 1995. Brain activity during transient sadness and happiness in healthy women. Am J Psychiat 152:341-351.

George MS, Ketter TA, Parekh PI, Herscovitch P, Post RM. 1996. Gender differences in regional cerebral blood flow during transient self-induced sadness or happiness. Biol Psychiat 40:859871.

Giedd JN, Vaituzis AC, Hamburger SD, Lange N, Rajapakse JC, Vauss YC, Rapoport JL. 1999. Quantitative MRI of the temporal lobe, amygdala, and the hippocampus in normal human development: Ages 4-18 years. J Comp Neurol 366:223-230.

Gloor P. 1986. Role of the human limbic system in perception, memory and affect: Lessons from temporal lobe epilepsy. In: Doane BK, Livingston KE, editors. The limbic system: Functional organization and clinical disorders. New York: Raven Press, $p$ $159-169$.

Grossman M, Wood W. 1993. Sex differences in intensity of emotional experience: A social role interpretation. J Pers Soc Psychol 65:1010-1022.

Gur RC, Mozley LH, Mozley PD, Resnick SM, Karp JS, Alavi A, Arnold SE, Gur RE. 1995. Sex differences in regional cerebral glucose metabolism during a resting state. Science 267:528-531.

Hamann SB, Timothy DE, Grafton ST, Kilts CD. 1999. Amygdala activity related to enhanced memory for pleasant and aversive stimuli. Nature Neurosci 2:289-293.

Heller W. 1990. The neuropsychology of emotion: Developmental patterns and implications for psychopathology. In: Stein NL, Leventhal B, Trabasso T, editors. Psychological and biological approaches to emotion. Hillsdale NJ: Erlbaum, p 167-211.

Hiscock M, Inch R, Jacek C, Hiscock-Kalil C, Kalil KM. 1994. Is there a sex difference in human laterality? I. An exhaustive survey of auditory laterality studies from six neuropsychology journals. J Clin Exp Neuropsychol 16:423-435.

Hughdal K, Iversen PM, Johnson BJ. 1993. Laterality for facial expressions: Does the sex of the subject interact with the sex of the stimulus face? Cortex 29:325-331.

Irwin W, Davidson RJ, Lowe MJ, Mock BJ, Sorenson JA, Turski PA. 1996. Human amygdala activation detected with echo-planar functional magnetic resonance imaging. NeuroReport 7:17651769.
Javanmard M, Shilk J, Kennedy SH, Vaccarino FJ, Houle S, Bradwejn J. 1999. Neuroanatomic correlates of CCK-4-induced panic attacks in healthy humans: A comparison of two time points. Biol Psychiat 45:872-882.

Ketter TA, Andreason PJ, George MS, Lee C, Gill DS, Parekh PI, Willis MW, Herscovitch P, Post RM. 1996. Anterior paralimbic mediation of procaine-induced emotional and psychosensory experiences. Arch Gen Psychiat 53:59-69.

Kring AM, Gordon AH. 1998. Sex differences in emotion: Expression, experience, and physiology. J Pers Soc Psychol 74:686-703.

LaBar KS, Gatenby C, Gore JC, LeDoux JE, Phelps EA. 1998. Human amygdala activation during conditioned fear acquisition and extinction: A mixed-trail fMRI study. Neuron 20:937-945.

Lane RD, Reiman EM, Ahern GL, Schwartz GE, Davidson RJ. 1997. Neuroanatomical correlates of happiness, sadness, and disgust. Am J Psychiat 154:926-933.

Lavadas E, Nicoletti R, Umilta C, Rizzolatti G. 1984. Right hemisphere interference during negative affect: A reaction time study. Neuropsychologia 22:479-485.

LeDoux JE. 1996. The emotional brain. New York: Simon and Schuster.

Levin JM, Ross MH, Mandelson JH, Mello NK, Cohan BM, Renshaw PF. 1998. Sex differences in blood-oxygenation-level-dependent functional MRI with primary visual stimulation. Am J Psychiat 155:434-436.

Maccby E, Jacklin C. 1974. The psychology of sex differences. Stanford: Stanford University Press.

Majeres RL. 1997. Sex differences in phonetic processing: Speed of identification of alphabetical sequences. Percept Motor Skills 85:1243-1451

Mayberg HS, Liotti M, Brannan SK, McGinnis S, Mahurin RK, Jerabek PA, Silva JA, Tekell JL, Martin CC, Lancaster JL, Fox PT. 1999. Reciprocal limbic-cortical function and negative mood: Converging PET findings in depression and normal sadness. Am J Psychiat 156:675-682.

McConatha JT, Leone FM, Armstrong JM. 1997. Emotional control in adulthood. Psychol Rep 80:499-507.

Miura SA, Schapiro MB, Grady CL, Kumar A, Salerno JA, Kozachuk WE, Wagner E, Rapoport SI, Horwitz B. 1990. Effect of gender on glucose utilization rates in healthy humans: a positron emission tomography study. J Neurosci Res 27:500-504.

Moretti MM, Charlton S, Taylor S. 1996. The effects of hemispheric asymmetries and depression on the perception of emotion. Brain Cogn 32:67-82.

Morris-Prather CE, Harell JP, Collins R, Leonard KL, Boss M, Lee JW. 1996. Gender differences in mood and cardiovascular responses to socially stressful stimuli. Ethn Dis 6:123-131.

Mu Q, Xie J, Wen Z, Shuyun Z. 1999. A quantitative MR study of the hippocampal formation, the amygdala, and the temporal horn of the lateral ventricle in healthy subjects 40 to 90 years of age. Am J Neuroradiol 20:207-211.

Murphy GM. 1986. The human medial amygdaloid nucleus: No evidence for sex difference in volume. Brain Res 365:321-324.

Otto MW, Yeo RA. 1993. Hemispheric activation, affective judgments, and pain perception. Psychother Psychosom 60:186-194.

Pardo JV, Pardo PJ, Raichle ME. 1993. Neural correlates of selfinduced dysphoria. Am J Psychiat 150:713-719.

Paus T, Otaky N, Caramanos Z, MacDonald D, Zijdenbos A, D'Avirro D, Gutmans D, Holmes C, Tomaiuolo F, Evans AC. 1996. In vivo morphometry of the intrasulcal gray matter in the human cingulate, paracingulate, and superior-rostral sulci: Hemispheric asymmetries, gender differences and probability maps. J Comp Neurol 376:664-673. 
Phillipps ML, Young AW, Senior C, Brammer M, Andrew C, Calder AJ, Bullmore ET, Perrett DI, Rowland D, Williams SC, Gray JA, David AS. 1997. A specific neural substrate for perceiving facial expressions of disgust. Nature 389:495-498.

Reiman EM, Lane RD, Ahern GL, Schwartz GE, Davidson RJ, Friston KJ, Yun LS, Chen K. 1997. Neuroanatomical correlates of externally and internally generated human emotion. Am J Psychiat 154:918-925.

Rolls ET. 1990. A theory of emotion, and its application to understanding the neural basis of emotion. Cogn Emotion 4:161-190.

Rolls ET. 1992. Neurophysiology and functions of the primate amygdala. In: Aggleton JP, editor. The amygdala: Neurobiological aspects of emotion, memory, and mental dysfunction. New York: Wiley-Liss, p 143-165.

Rowland D, Young AW, Calder AJ, Dolan RJ, Morris JS, Frith CD, Perrett DI. 1996. A differential neural response in the human amygdala to fearful and happy facial expressions. Nature 383: 812-815.

Schlösser R, Hutchinson M, Joseffer S, Rusinek H, Saarimaki A, Stevenson J, Dewey SL, Brodie JD. 1998. Functional magnetic resonance imaging of human brain activity in a verbal fluency task. J Neurol Neurosurg Psychiat 64:492-498.

Schneider F, Gur RC, Gur RE, Muenz LR. 1994a. Standardized mood induction with happy and sad facial expressions. Psychiat Res 51:19-31.

Schneider F, Gur RC, Jaggi JL, Gur RE. 1994b. Differential effects of mood on cortical cerebral blood flow: A ${ }^{133}$ Xenon clearance study. Psychiat Res 52:215-236.

Schneider F, Gur RE, Harper Mozley L, Smith RJ, Mozley PD, Censits DM, Alavi A, Gur RC. 1995. Mood effects on limbic blood flow correlate with emotional self-rating: A PET study with oxygen-15 labeled water. Psychiat Res: Neuroimaging 61: 265-283.

Schneider F, Grodd W, Weiss U, Klose U, Mayer KR, Nägele T, Gur RC. 1997. Functional MRI reveals left amygdala activation during emotion. Psychiat Res: Neuroimaging 76:75-82.

Schneider F, Weiss U, Kessler C, Salloum JB, Posse S, Grodd W, Müller-Gärtner HW. 1998. Differential amygdala activation in schizophrenia during sadness. Schizophrenia Res 34:133142.

Shaywitz BA, Shaywitz SE, Pugh KR, Constable RT, Skudlarski P, Fulbright RK, Bronen RA, Fletcher JM, Shankeiler DP, Katz L, Gore JC. 1995. Sex differences in the functional organization of the brain for language. Nature 373:607-609.

Shtasel DL, Gur RE, Mozley PD, Richards J, Taleff MM, Heimberg C, Galacher F, Gur RC. 1991. Volunteers for biomedical research: Recruitment and screening of normal controls. Arch Gen Psychiat 48:1022-1025.

Teasdale JD, Howard RJ, Cox SG, Ha Y, Brammer MJ, Williams SC, Checkley SA. 1999. Functional MRI study of the cognitive generation of affect. Am J Psychiat 156:209-215.

Volkow ND, Wang GJ, Fowler JS, Hitzemann R, Pappas N, Pascani K, Wong C. 1997. Gender differences in cerebellar metabolism: Test-retest reproducibility. Am J Psychiat 154:119-121.

Watson D, Clark LA, Tellegen A. 1988. Development and validation of brief measures of positive and negative affect: The PANAS scales. J Pers Soc Psychol 54:1063-1070.

Weiss U, Salloum JB, Schneider F. 1999. Correspondence of emotional self-rating with facial expression. Psychiat Res 86:175-184. 